\title{
CONFIGURATION SELECTION FOR A 450-PASSENGER ULTRAEFFICIENT 2020 AIRCRAFT
}

\author{
D. Paulus ${ }^{1}$, T. Salmon ${ }^{2}$, B. Mohr ${ }^{1}$, C. Roessler ${ }^{1}$, \\ Ö. Petersson ${ }^{3}$, F. Stroscher ${ }^{3}$, H. Baier ${ }^{3}$, and M. Hornung ${ }^{1}$ \\ ${ }^{1}$ Institute of Aircraft Design \\ Technische Universität München \\ 15 Boltzmannstrasse, Garching 85747, Germany \\ ${ }^{2}$ AIRBUS \\ 1 Rond Point Maurice Bellonte, Blagnac Cedex 31707, France \\ ${ }^{3}$ Institute of Lightweight Structures \\ Technische Universität München \\ 15 Boltzmannstrasse, Garching 85747, Germany
}

This paper describes the configuration selection process in the FP7 project ACFA (Active Control for Flexible Aircraft) 2020 in view of the Advisory Council for Aeronautics Research in Europe (ACARE) aims. The design process challenges and the comparison of a blended wing body (BWB) aircraft with a wide body carry-through wing box (CWB) configuration are described in detail. Furthermore, the interactions between the conceptual design and structural design using multidisciplinary design optimization (MDO) to rapidly generate and adapt structural models to design changes and provide early feedback of mass and center of gravity values for these nontraditional configurations are discussed. Comparison of the two concepts determined that the developed all-lifting BWB airframe has the potential for a significant reduced fuel consumption compared to the CWB.

\section{INTRODUCTION}

Highly efficient future aircraft configurations are needed in order to cope with ever growing air traffic and to sustain and improve passenger comfort and freight 
requirements. The configurations within ACFA are designed to the growing mid-range and long haul market segment of 400 passengers and beyond. Airbus considers the biggest market share with 42 percent order value from 2010 to 2029 to be taken by mid-size twin aisle aircraft. If long range large aircraft are included, new order value rises to $60 \%$ [1].

Further information on the background of the ACFA configuration and its research aims can be found in [2].

Since active control directly influences not only the control surfaces, the conventional aircraft design process had to be adapted early in the development of the unconventional aircraft designs discussed in this paper.

Tailless aircraft configurations with wing-fuselage blending potentially offer low fuel consumption, mainly achieved by drag reduction, reduced structural weight, and through the significantly lower wetted area ratio [3-5]. Exterior noise can be minimized by an advanced high-lift system or by shielding of the engines [4].

Airframe development for a BWB and a wide body configuration with CWB, as the basis for further control studies, was conducted within the first year of the project.

Hence, this paper discusses the conceptual aircraft design and selection process of a highly efficient BWB and CWB configurations on a specified design mission. Commencing with the requirement definition, the challenges and development methods are depicted.

The main body will show the results of the design process with a special focus on the MDO of the fuselage and wing box. Systematically comparing the developed configurations led to an aircraft selection which is most suitable for the proposed mission.

\section{REQUIREMENTS AND MISSION DEFINITION}

A set of requirements was established in discussion with project partners [6]. The most relevant requirements are given in Table 1. As shown, global market outlook perspectives also influenced the requirement and configuration finding process.

\subsection{Operational Performance}

Global requirements commence with the mission definition as shown in Table 1. The development focuses on a carrier design for at least 460 passengers (Pax) on a 7200 nautical mile mission in a two-class layout. Flight altitude is $33000 \mathrm{ft}$ and above with a cruise Mach number of 0.85 . The aircraft shall be able to fly at its optimum altitude during the entire cruise phase for which climb and 
Table 1 Global requirements of ACFA mission definition

\begin{tabular}{ll}
\hline \multicolumn{1}{c}{ Parameter } & \multicolumn{1}{c}{ Value } \\
\hline Approach speed & $<150 \mathrm{kt}$ \\
Range & $\geq 7200 \mathrm{~nm}$ \\
Cruise Mach number & 0.85 \\
Initial cruise altitude & $\geq 33000 \mathrm{ft}$ \\
Pax & $\geq 460 \mathrm{in} \mathrm{a} \mathrm{two-class} \mathrm{layout}$ \\
\hline
\end{tabular}

buffet ceilings were defined. For slow approaches, the speed of below 150 knots is considered to be optimal [4].

\subsection{Passenger Cabin and Landing Gear Definition}

For the BWB, the baseline layout is a two-class arrangement with a total of 470 passengers in a business (BC) / economy (YC) class splitting of 56/414. On the other hand, the CWB has a two-class arrangement with 464 passengers in $\mathrm{BC} / \mathrm{YC}$ splitting of $60 / 404$. For the landing gear, a wheel track of less than $16 \mathrm{~m}$ (International Civil Aviation Organization (ICAO) Code F) and a rotation clearance angle of greater than $11^{\circ}$ shall be achieved.

\subsection{Lifting Surface Requirements}

New aircraft wing span is restricted to $80 \mathrm{~m}$ under the ICAO Code F. Winglets for yaw control in case of one engine inoperative are an option. The leading edge sweep angle shall be $55^{\circ}$ for the BWB centerbody.

The BWB outer wing and CWB wing sweep and relative thickness need to be designed in order to optimize the fuel burn of the overall aircraft in an aerodynamic performance/weight trade-off. Hence, the BWB centerbody's maximum relative thickness should not exceed $17 \%$. The spanwise load distribution target is elliptic as it has been identified as a potential optimum since a large part of the flying wing structure is not sized by aerodynamic loading but by pressurization.

\subsection{Fuel Capacity}

Fuel capacity is set to be greater than maximum takeoff weight (MTOW) minus operating weight empty (OWE) plus 0.7 times 2-class payload. For 464 passengers and an assumed $105 \mathrm{~kg}$ per passenger, the payload adds up to $48720 \mathrm{~kg}$. 
This results in a basic fuel capacity formula:

$$
\text { Fuel > MTOW - OWE - 34104 kg }
$$

\section{DESIGN PROCESS}

This section describes the design methods and process applied for CWB and BWB configurations based on the preceding requirements definition.

\subsection{Structural Weight}

\subsubsection{Fuselage design}

The fuselage was sized according to the cabin and passenger requirements. For unconventional fuselage shapes, the methods applied for current commercial aircraft with an aft empennage are not applicable. Foregoing parametric studies of cross section with different radii and structural thickness were optimized in close cooperation with the Institute of Lightweight Structures (see section 5). The cabin integration for unconventional aircraft designs revealed the necessity of using finite element models (FEMs) to obtain mass and center of gravity estimates for the fuselage as conventional statistical equations cannot be applied for the unconventional cross section. For both layouts, it was optimized for crosssectional and wetted areas. In addition, the provision of 6 exits at each side and an easy loading and unloading of the unit load devices 3 (LD3) and pallets is envisaged. A cruise angle of attack at $1.7^{\circ}$ can be considered as comfortable (below $3^{\circ}$ ).

\subsubsection{Wing}

The Luftfahrttechnisches Handbuch (LTH), a German aerospace publication for civil and military aircraft applications [7], was used for BWB and CWB wing weight calculations and also applied for the slats, flaps, and ailerons including paint. After the establishment of the FEM, wing weight calculations were compared with the analytical model and finite elements results were used for more detailed concept development.

\subsubsection{Conventional structural elements}

The weight of the structural elements which do not significantly differ from conventional design were computed from the LTH. The results were either directly calculated or validated with published data. As mentioned above, the fuselage 
primary structure was designed with a FEM. Secondary structure elements such as cabin and cargo floors, doors, landing gear (main/front), cockpit and cabin windows, horizontal and vertical stabilizers, engines including the controls, subsystems, oxygen, and deicing systems were also calculated according to LTH. Further systems in this calculation included communication, electric wiring, furnishing, water installation, and operator items.

\subsection{Aerodynamics and Control}

\subsubsection{Subsonic}

To ensure the comparability of the CWB to the BWB configuration, the same methods and approach for both configurations were used. The core is a combination of empirical equations to calculate the aerodynamic efficiency at trimmed conditions. With these equations, variable parameters have been optimized to get maximum aerodynamic efficiency at different angles of attack and flight altitudes. In addition, a vortex lattice method with three-dimensional (3D) panels was used to develop the profiles and to calculate pressure and lift distributions. The BWB requires specially designed airfoils as stability has to be achieved through sweep and twist adjustments. The center section has to accommodate the cabin box which decreases aerodynamic performance in the transonic speed region. The 3D target lift distribution was achieved by iterating the local twist and spanwise twist with specially adapted airfoils with a half span partition in 5 wing panels. Hence, low lift coefficients are required in the middle section and higher lift coefficients at the outer parts of the wing. A twist distribution for near-elliptic lift was identified as best with regard to aerodynamic performance measured by the glide ratio or total drag at the design cruise condition.

\subsubsection{Transonic}

For the transonic regime, aerodynamics are especially challenging in conceptual design. As with many aspects for unconventional aircraft, analytical methods inaccurately describe the physical effects of shock and wave drag effects. The Lock formula described and adapted by Malone and Mason [8] for the estimation of wave drag effects is sufficient for preliminary estimates [5]. For the validation, a comparison with already available aerodynamic computations conducted within Airbus has been performed.

\subsubsection{Stability and control}

The flight control surfaces of the ACFA BWB at this stage are ailerons, elevators, winglet rudders, slats, and flaps in addition to spoilers and airbrakes. Unlike the 
CWB, no horizontal tail for trim can be used to trim the BWB. Instead sweeping the wing and twisting, the outer wing section is necessary. The influencing factors for flight control analysis in the preliminary design phase are weight in terms of MTOW and total wing span. Stability was analyzed with a software combining lifting line with vortex lattice and a 3D panel method. Additional analysis was conducted with calculations and available test data [9] based on [10].

\subsection{Engine}

The generic and scalable engine model used was provided by Airbus. It comprises a $115 \mathrm{klb}$ takeoff thrust engine and its characteristics during takeoff, climb, and cruise regarding available thrust and fuel consumption. The model provided data for all relevant flight altitudes and temperature offsets from International Standard Atmosphere (ISA) (Fig. 1).

Since two pylon-mounted engines are located over the centerbody of each configuration, scaling rules for the adaption of weight, specific fuel consumption (SFC), and dimensions were also implemented in agreement with Airbus. The takeoff and initial climb is the driving segment for the sizing of the engines and highly depend on the aerodynamic efficiency during acceleration and rotation. As in the conceptual development stage, the assessment of low-speed aerodynamics and takeoff speeds is preliminary, a fixed thrust to weight ratio of 0.27 for both BWB and CWB was assumed. The engine size was computed according to

$$
F_{\text {engine }}[\mathrm{lbf}]=\frac{0.27 \mathrm{MTOW}[\mathrm{kg}] \cdot 9.81\left[\mathrm{~m} / \mathrm{s}^{2}\right]}{4.448222[\mathrm{lbf} / \mathrm{N}] \cdot n_{\text {engines }}}
$$

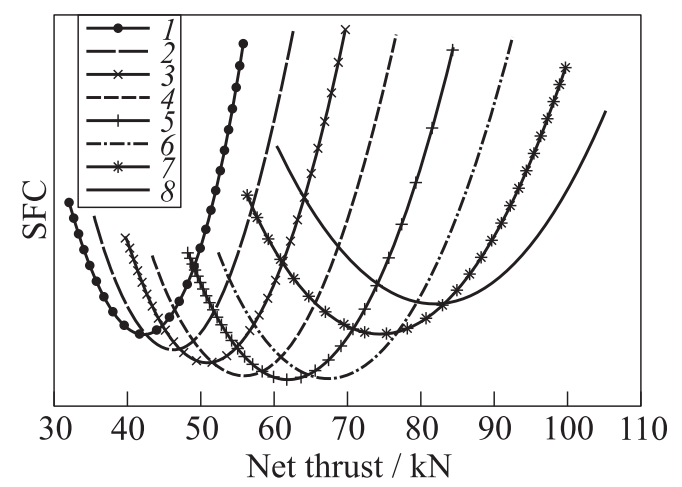

Figure 1 Cruise SFC curves for BWB in different altitudes: $1-45 \mathrm{kft} ; 2-43$; $3-41 ; 4-39 ; 5-37 ; 6-35 ; 7-33$; and $8-31 \mathrm{kft}$ 


\section{MULTIDISCIPLINARY DESIGN OPTIMIZATION IN THE STRUCTURAL PROCESS}

Details of the structural design of both ACFA 2020 aircraft concepts are given in the corresponding reports [11,12]. Both concepts considered in the ACFA project are unconventional in nature, particularly, with respect to the fuselage designs. The applicability of traditional statistically based mass estimation routines must, therefore, be examined critically. In the case of the BWB configuration, the ACFA project was able to build upon experience from previous European framework programmes such as Very Efficient Large Aircraft (VELA) and New Aircraft Concepts Research (NACRE). For the CWB configuration, however, few data points were available. The design and mass estimate of the CWB fuselage was, therefore, performed in a closely coupled MDO process iterating between conceptual and structural design.

Given the width of the cabin, a conventional circular cross-section pressure vessel is intangible for the CWB fuselage design as this would lead to too much wasted space. Initial studies including, for example, elliptical cross sections quickly led to a so-called double bubble design as a good compromise between cross-sectional area and resistance to internal pressure loads. This design consists of two side-by-side pressure vessels supported by frames with a double spherical section pressure bulkhead at the rear of the cabin. In the center, vertical struts connect the frames at the top and bottom surface and the floor beam. To determine the cross-sectional shape, a finite-element half model of a section through the fuselage consisting of two frames, the outer skin, floor, and central supports was created and used as a basis of a multiobjective optimization of the structure (see Figs. 2 and 3). The shape of the cross section is given by four splines with support points at the corners of the boxes defining the payload volume provided by Airbus. The optimizer varies the distance of each control point from the payload circled in Fig. 2 and the slope of the spline as well as the height of the frames at each point. An internal pressure of 1 bar is applied to the skin and symmetrical boundary conditions applied at the center line. Thickness of the skin and frames was kept constant. In addition to geometric constraints, the major principal strain in the structure was not allowed to exceed $5 \%$. Material was quasi-isotropic carbon fibre. The objective of the optimization was the minimization of a weighted sum of the normalized mass and the total cross-sectional and wetted areas of the section.

After running the optimization with varying weighting of the two objectives, the resulting shapes and sectional masses were discussed with the conceptual design team resulting in the selection of the cross section shown in Fig. 3 with the mass of the section serving as basis for the fuselage mass estimate.

In the case of the CWB wing box, outer geometry was determined during the conceptual design stage as well as the positions of front and rear spars. Position 


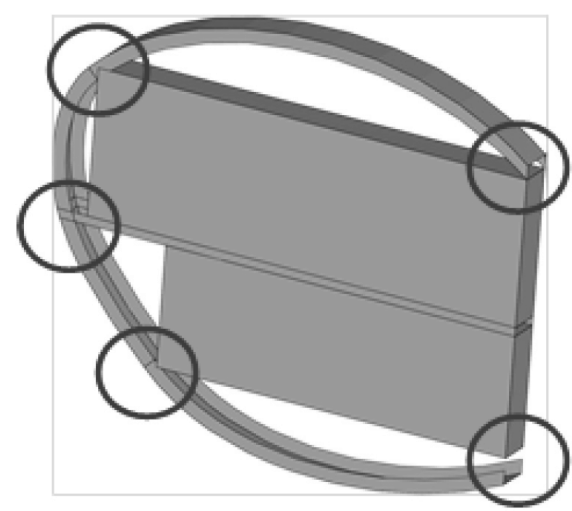

Figure 2 Design of the cross section: circled points indicate design points of the spline; boxes are the prescribed dimensions for cabin and freight volume

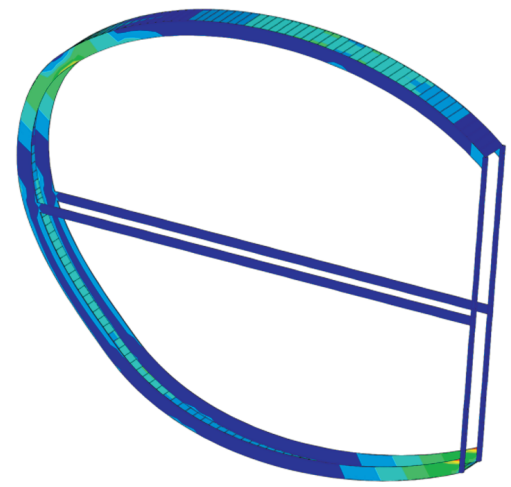

Figure 3 Major principal strain in the fuselage cross section due to an internal pressure of 1 bar. Maximum strain (red) at $4.6 \%$.

and length of a center spar were free to change during the structural design. The CWB wing is thin and relatively highly swept but is generally of a conventional configuration and thus expected to show good correspondence to statistical mass estimations.

To obtain a good configuration for the positioning of the wing box ribs, a parameterized FEM of the wing box was created as shown in Fig. 4 where the outer skin has been removed in the figure to expose the ribs and center spar. In this model, the position and length of the front and rear spars are constant along with the wing profile, twist and dihedral. Spacing of the ribs in the wing box can be varied as well as the angle between the ribs and the front spar. The chordwise position of the center spar, its sweep, and length can also be varied in the model. The model has symmetric boundary conditions on the center plane. Elliptical pressure loads simulating lift of a $2.5 \mathrm{~g}$ pull-up manoeuvre and of a $-1.0 \mathrm{~g}$ pushover manoeuvre are applied in two separate load cases with the weight of the fuselage included as distributed forces on the center part of the wing-box in each case. Spar webs and ribs are constructed of quasi-isotropic carbon-fiberreinforced polymer (CFRP), wing skin and spar caps are highly orthotropic to take advantage of the well-defined load paths. Stringers in the outer skin are modeled using layered shell elements; the top layer corresponding to the wing skin itself and subsequent layers to the stringer webs and caps. These subsequent layers, therefore, have near-zero stiffness orthogonal to the stringers as well as a near-zero shear stiffness. 


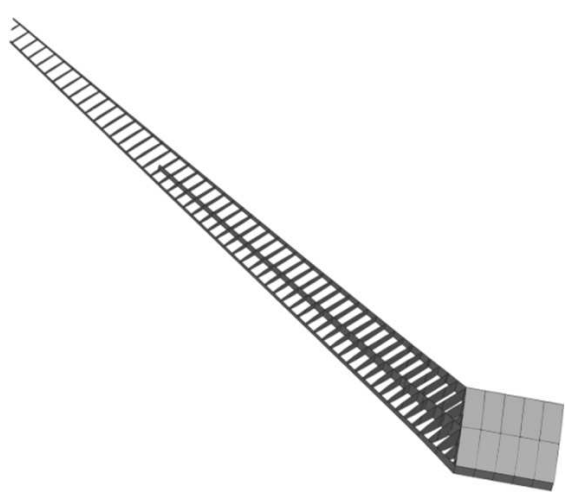

Figure 4 Parameterized model of the internal structure of the CWB with variable rib spacing and angle as well as center spar position and length

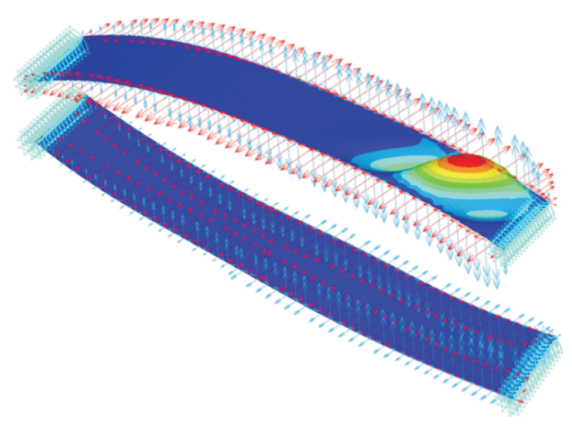

Figure 5 Buckling field between two ribs in the wing box.

A parameter study of the internal structure of the wing box was performed using a genetic algorithm [13]. Apart from the geometric variables described above, the thickness of the wing skin and spar webs was also varied by the algorithm. In the model, constraints are placed on the displacement at the tip and the major and minor principal strains in the structure. As the primary failure mode of the wing skin is expected to be skin buckling, however, a separate model was used to assess the stability of the skin as seen in Fig. 5. During each evaluation, a skin panel between two ribs near the wing root is automatically exported, remeshed with a finer element size and the section forces from the global model applied for each of the two load cases. Finally, a linear buckling analysis is performed and the resulting load factor is returned to the genetic algorithm.

The objective function of the genetic algorithm was the mass of the wing box. After around 15 generations with a population size of 60 , the algorithm had converged to a solution with a rib spacing of around $800 \mathrm{~mm}$ and an angle between ribs and front spar of about $95^{\circ}$. Buckling strength in both load cases was the limiting constraint.

With the finalized topology of the wing box structure, a structural sizing optimization of the finite element half-model including the fuselage, tail, and simplified engine mountings was performed. Mass modeling was performed in cooperation with the conceptual design distributing nonstructural masses representing landing gear and other equipment in the fuselage according to the conceptual mass estimate. Likewise, a mass point representing the engine is positioned at the center of gravity of the engine and connected by rigid beams to 


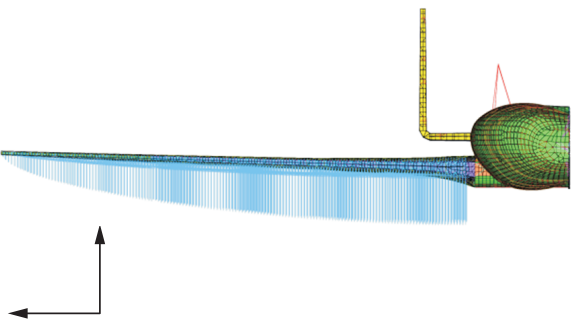

Figure 6 Elliptical lift distribution applied to the wing distribution for structural sizing.

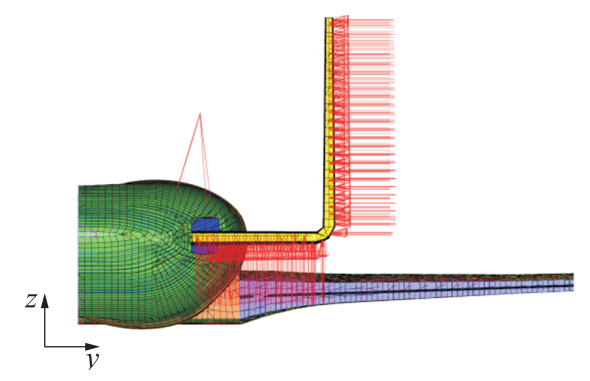

Figure 7 Static load on the tail.

the fuselage. Fuel masses are distributed in the wing and connected via rigid body elements to the wing box. Symmetric boundary conditions are applied at the center plane. An elliptical pressure distribution representing the lift in both the positive $2.5 \mathrm{~g}$ manoeuvre case as well as the $-1.0 \mathrm{~g}$ manoeuvre was applied to the wing (Fig. 6), a constant pressure to the tail surfaces (Fig. 7), and an internal pressure of 1.4 bar to the fuselage between the pressure bulkheads at the rear and the nose.

Improving on the modeling described previously, the stringers in the wing skin were modeled as beam elements with the skin as a single layer orthotropic shell. Stringers in the fuselage, tail, and stabilizers were modeled in the same manner.

The sizing optimization of the half-model comprised 54 design variables consisting of the thickness of the wing skin separated into several design zones, thickness of the fuselage skin similarly separated into zones and thickness of the stabilizer skin, shear webs of the fuselage frames, as well as spars and ribs in the wing and stabilizer. Dimensions of the stringers in the wing, stabilizers, and pressure hull were also variable as well as those of the caps of spars and ribs in the wing and stabilizer in addition to the caps of the frames in the fuselage. Elastic strain in the structure was constrained to remain within $\pm 5 \%$. The objective of the optimization was minimum structural mass.

Convergence was generally rapid with a candidate optimal solution usually delivered in less than 35 iterations with stringent convergence criteria. Starting the optimization from several starting points resulted in the selection of an optimum design on which to base the final structural design.

The design resulting from the sizing optimization is intuitive: strength limited components (i. e., those close to the strain limit) are the wing skin near the wing root, the fuselage skin where the wing box passes through the hull, and the 
stringers in the wing to around $2 / 3$ of the span. Similarly intuitive, the thickness of the wing skin falls when going from root to tip and thicknesses of shear webs in spars and frames tend to their minimum values as no constraints on the stability of these components were included. Sizing variables of the stabilizers all tend to their minimum values indicating that the loads applied to them might need to be reviewed.

Comparing the mass of the final structural design with the initial mass estimates of the conceptual design results in a difference of around $5 \%$ for the wing with the structural model mass being greater. This relatively small difference is consistent with the conventional design of the wing. In the case of the fuselage, the structural model mass is almost $15 \%$ lighter than the conceptual design despite the latter being based on the original finite element section model. Similarly, the mass of the stabilizers in the structural model is $20 \%$ less than the initial estimate. The most likely explanation for these discrepancies is lack of dimensioning load cases such as the impact at landing or the loss of an engine at takeoff as well nonconservative sizing rules for the shear webs and skins in the hull considering only static strength and not stability.

Finally, a more detailed aeroelastic tailoring was performed of the wing box in isolation [14]. Mass and inertia properties of the rest of the structure were concentrated at a mass point located at the center of gravity and this connected to the wing box using rigid elements as shown in Fig. 8. Modeling of the tail was greatly simplified. It was connected to the mass point at the center of gravity using beam elements, the mechanical properties of which were

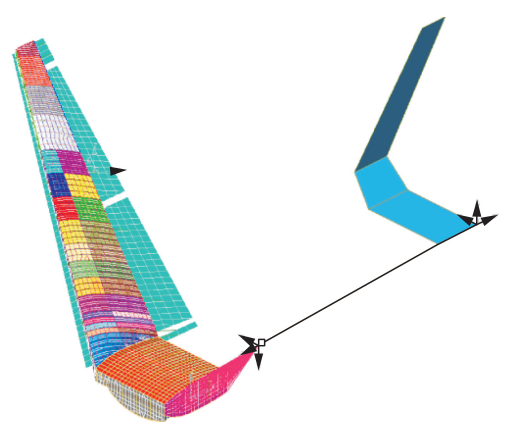

Figure 8 Finite element model of wing with simplified tail surfaces for aeroelastic tailoring.
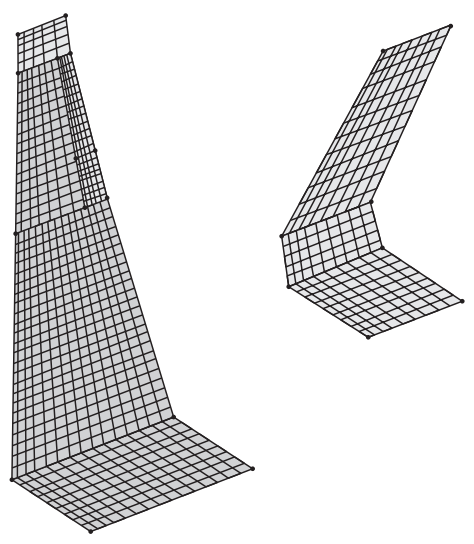

Figure 9 Doublet lattice aerodynamic model mesh of wing and tail including split aileron vertical stabilizer and trim surface 
determined from the detailed FEM of the fuselage. Flaps and slats were included as plates with approximated mass and stiffness properties and fastened to the wing box without stiffening it in bending. Boundary conditions were applied at the center of gravity; both symmetric and antisymmetric cases were included.

In addition to the structural model, a doublet lattice aerodynamic model (DLM) was created as shown in Fig. 9. The aerodynamic model includes the wing and tail surfaces as well as the split aileron.

The $2.5 \mathrm{~g}$ and $-1.0 \mathrm{~g}$ static load cases were simulated by trimming the aircraft with the corresponding constant vertical acceleration using the horizontal tail surface (excluding the part of the tail contained within the fuselage). In addition, positive and negative roll manoeuvres due to deflection of each of the ailerons or both of them together were included. The response to discrete $1-\cos$ gusts of varying lengths was also assessed.

For the aeroelastic tailoring, the wing skins were modelled as four layered shells with one layer for each fibre orientation, $0^{\circ}, 90^{\circ}$, and $\pm 45^{\circ}$ with properties smeared across the thickness of the shell. The optimizer was free to vary the thickness of each layer separately. Constraints, as before, were placed on the elastic strain in the material. Additionally, a constraint was placed on the minimum steady-state roll rate to ensure control effectiveness and on the difference between first bending and torsional eigenfrequencies to avoid flutter problems. The objective, as before, was a minimum mass.

The tailored design does not differ greatly from the previous sizing of the wing box except at the outer $1 / 3$ of the span where additional stiffness and, therefore, material must be added to the wing to ensure compliance with the roll effectiveness constraint. The critical gust loads (both positive and negative) also lead to excessive strains in this region requiring reinforcement whereas the strength at the wing root after sizing for the static manoeuvre cases is adequate. The main reason for the critical loads at this location is the fact that here, the center spar ends, modifying the shear flow for torsional loads.

\section{CONFIGURATION SELECTION}

The one-year conceptual design process demonstrated the feasibility of both aircraft concepts. Selected results will be presented in this section leading to a comparison and, thus, selection of the BWB concept over the CWB design.

\section{$5.1 \quad$ Results}

Selecting a future aircraft layout within the ACFA framework was conducted based on a detailed trade-off analysis comprising the categories geometry, aero- 

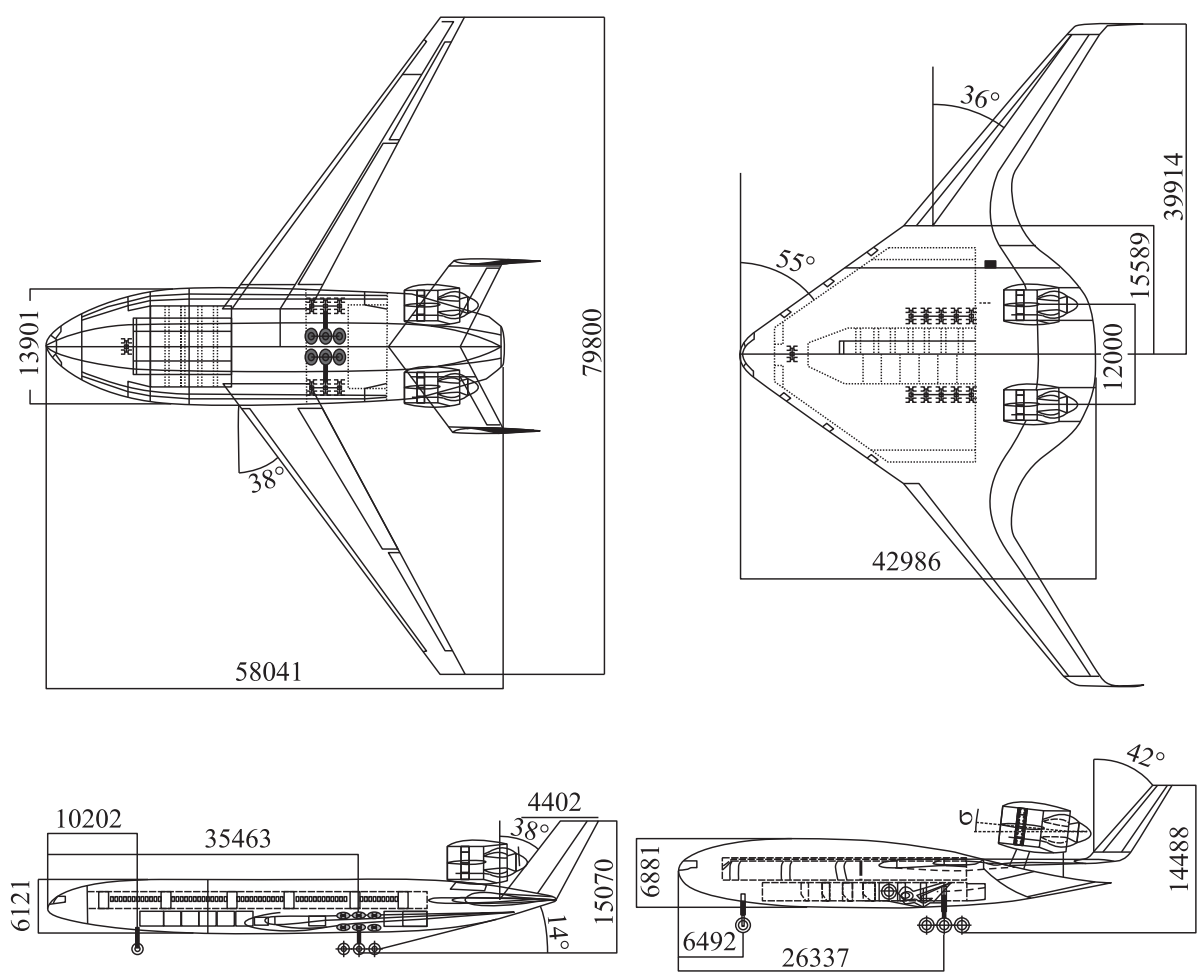

(a)

(b)

Figure 10 Overview of CWB $(a)$ and BWB $(b)$. Dimensions are in millimeters

dynamics, weights, and mission performance. The work in this section represents first year-end collaborative research results $[6,15]$. Figure 10 depicts the two basis configurations with their main dimensions.

\subsubsection{Geometry}

The CWB in its final configuration has a wing aspect ratio of 10.83 whereas the BWB due to its unconventional form has a ratio of only 4.82 . One reason being the 80-meter wing span limitation. The all-lifting BWB airframe results in a low required center line in cruise and low induced drag.

The increased lifting surface and reference area of the BWB potentially increases low speed lift. The detailed trade-off for cruise drawbacks for flying in higher altitudes can be significant. Although the reference area of the BWB is 
much larger, the overall wetted area is $3.6 \%$ less leading to lower zero lift friction drag. Taper ratios are 0.09 for the BWB and 0.29 for the CWB.

The fuselage accommodating the passenger cabin is $14.77 \mathrm{~m}$ longer in the case of the CWB. The reason is the widening of the cabin box along the $y$-axis in the BWB. Effects on ride comfort were evaluated later in the project. The current CWB and BWB configurations are spaced for at least 30 LD3 containers. Both concepts position the engines on top of the fuselage with possible shielding effects expected to be larger for the BWB. However, no significant structural advantages are expected, since the structural reinforcements of conventional under wing engine mounting are also required for the envisaged central aft mounting.

For yaw control, the CWB configuration uses double fins with rudders where the BWB uses winglets with a rudder chord of $30 \%$ of the winglet. Trim is also challenging. All trailing edge moveables are needed on the BWB. In comparison, the CWB has a heavy moveable h-tail which more easily and with fewer flight dynamics interactions counteracts center of gravity shifts during flight. Damping capabilities for flight stability are generally lower on the BWB due to smaller lever arms and higher coupling effects. However, more sophisticated approaches are necessary to perform the detailed stability and performance assessment.

\subsubsection{Aerodynamic performance and stability}

The BWB has a better $L / D$ at the reference Reynolds number and a very low $\mathrm{C}_{D 0}$ as the ratio of wetted area to $S_{\text {ref }}$ is lower. As the BWB aspect ratio is also low, induced drag increases rapidly with $\mathrm{C}_{L}$ and leads to very low optimum $\mathrm{C}_{L}$ of 0.25 for the BWB. Opposite effects lead to a higher optimum $\mathrm{C}_{L}$ of 0.47

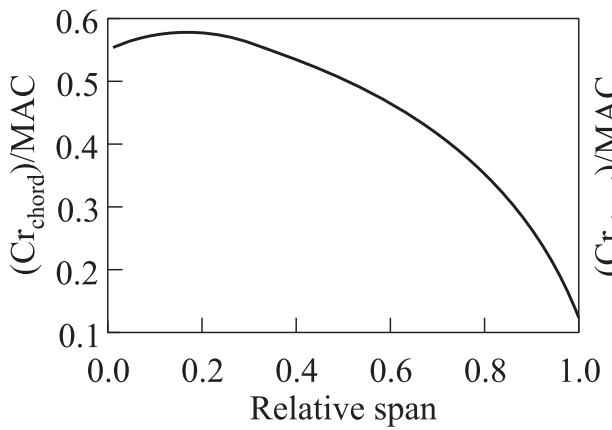

(a)

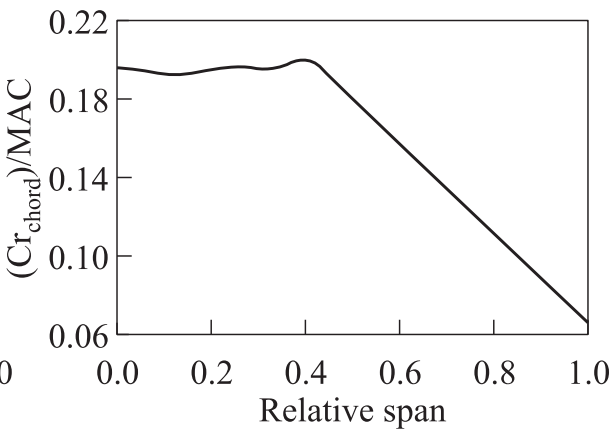

(b)

Figure 11 The ACFA CWB $(a)$ and BWB (b) lift distributions 
on the CWB [15]. Hence, for the total lift force in cruise, the lower $\mathrm{C}_{L}$ for the $\mathrm{BWB}$ requires a larger wing area.

Figure 11 depicts the lift distribution along the span for CWB and BWB. Carry-through wing box distribution is close to an elliptic lift distribution which results in low induced drag. Figure $11 b$ shows the lift distribution of the BWB at the due date of the configuration selection and indicates the need for further modification of the lifting body geometry. The final configuration and lift distribution is presented in [5].

Stability analysis revealed a slightly stable (1\% static margin) configuration and the need for more detailed models as the margin range is small and the exact determination in preliminary design with conventional methods is challenging.

\subsubsection{Weights}

Comprehensive data for all system and structure weights was computed. Especially for highly complex elements of the overall aircraft, the methods from conventional aircraft design need more refinement. The BWB experiences a weight advantage of $14.10 \mathrm{t}$. The horizontal and vertical stabilizers on the CWB add a 25.6 percent weight penalty, as conventional tail horizontal stabilizers on the BWB are nonexistent. As operator items are assumed to be equal for both configurations, the BWB achieves an OWE advantage of $9.7 \mathrm{t}$ over the CWB. Both configurations are separated by a 23.79-ton MTOW advantage for the BWB.

\subsubsection{Engine}

Based on the calculations in preliminary design and the CWB's lower optimum altitude, CWB thrust per engine is $126.7 \mathrm{klb}$ sized for the minimum thrust to weight ratio $(T / W)$ ratio of 0.27 . Blended wing body cruise and stepped altitude requirements lead to thrust of $119.6 \mathrm{klb}$ per engine.

\subsection{Aircraft Selection}

As the conceptual aircraft design has revealed, both configurations offer promising advantages for future air transport (Table 2). The BWB's weight benefit is significant and the inferior cruise and, thus, fuel burn performance of the CWB whose cruise $L / D$ is 21.7 compared to 24.2 of the BWB is a further disadvantage. The higher flight altitudes for the BWB and, thus, the required engine thrust does not exceed what current engines available on the market can deliver. 
Table 2 Mission performance comparison for BWB and CWB [15]

\begin{tabular}{cccc}
\hline Parameter & BWB & CWB & $\Delta, \%$ \\
\hline TOW & $401.6 \mathrm{t}$ & $428.4 \mathrm{t}$ & -6.7 \\
OWE & $255.0 \mathrm{t}$ & $234.7 \mathrm{t}$ & 8.0 \\
2-class Pax capacity & 470 & 464 & 1.3 \\
Engine size & $119.6 \mathrm{klb}$ & $12.7 \mathrm{klb}$ & -5.9 \\
CL of $(L / D)_{\max }$ & 0.25 & 0.47 & \\
$(L / D)_{\max }$ & 24.2 & 21.7 & 10.3 \\
\hline \multirow{2}{*}{ Block fuel 4000 nautical miles } & $62.03 \mathrm{t}$ & $68.16 \mathrm{t}$ & \\
& $131.8 \mathrm{~kg} / \mathrm{pax}$ & $146.9 \mathrm{~kg} / \mathrm{pax}$ & -11.5 \\
\hline \multirow{2}{*}{ Block fuel 7200 nautical miles } & $116.47 \mathrm{t}$ & $130.25 \mathrm{t}$ & \\
& $247.8 \mathrm{~kg} / \mathrm{pax}$ & $280.7 \mathrm{~kg} / \mathrm{pax}$ & -13.3 \\
\hline Initial cruise altitude capability & $36000 \mathrm{ft}$ & $33100 \mathrm{ft}$ & 8 \\
TTC at $31000 \mathrm{ft}$ & $25.6 \mathrm{~min}$ & $25.6 \mathrm{~min}$ & 0 \\
\hline
\end{tabular}

For its superior mission performance in fuel consumption on a 7200-nautical-miles (4000-nautical-miles) mission, the BWB beats the CWB by more than $13 \%$. No development obstacles have been identified; hence, the BWB was studied and optimized in the detailed development phase of the ACFA 2020 project.

\section{CONCLUDING REMARKS AND OUTLOOK}

Within the project time frame of one year, two conceptual commercial aircraft designs for a long haul mission were developed and compared based on a comprehensive set of requirements. The selection process was driven by the mission performance calculations based on geometric, aerodynamic, and weight analysis. Further, a comprehensive MDO was performed to optimize fuselage cross section and wing box design.

The selection of the BWB is a result of its superior efficiency. Compared to an improved wide body design such as the $\mathrm{CWB}$, the mission performance results in $15.46 \mathrm{t}$ less fuel burn with corresponding $\mathrm{CO}_{2}$ savings.

Ongoing research in the field of aircraft design addresses the preliminary design process adoptions and the design for active control technologies [5]. Especially in the areas of stability analysis, transonic aerodynamics, and structure, conventional methods need adjustments in order to efficiently apply them in conceptual design. Ride comfort and passenger acceptance as well as the inclusion of these radical configurations in the controlled airspace are the issues necessitating further research. 
Additional improvements to reach the ACARE goals and to lower fuel consumptions beyond what can be achieved by new airframe designs are expected from innovative engine technologies and more efficient air traffic management.

\section{ACKNOWLEDGMENTS}

The research described within this paper has received funding from the European Community's 7th Framework Programme (FP7/2007-2013) under grant agreement No. 213321.

The authors are very much indebted to all ACFA 2020 partners for their contributions. The authors are especially grateful to R. Maier and A. Wildscheck from EADS-IW and J.-J. Mirat from Airbus for their continuous support. The authors would also like to thank participating colleagues K. Ploetner and B. Brueckner from Technische Universität München. Finally, we would like to thank W. Staudacher for his valuable contributions concerning the overall aircraft configuration.

\section{REFERENCES}

1. Leahy, J. 2010. Airbus global market forecast 2010-2029. Toulouse.

2. Maier, R. 2013. ACFA 2020 - an FP7 project on active control of flexible fuel efficient aircraft configurations. In: Progress in flight dynamics, guidance, navigation, control, fault detection, and avionics. Eds. Ch. Vallet, D. Choukroun, Ch. Philippe, G. Balas, A. Nebylov, and O. Yanova. EUCASS advances in aerospace sciences book ser. Moscow: TORUS PRESS. 6:585-600.

3. Liebeck, R. H. 2004. Design of the blended wing body subsonic transport. J. Aircraft 41(1):10-25.

4. Hileman, J. I., S. Z. Spakovszky, and M. Drela. 2007. Airframe design for "Silent Aircraft." 45th AIAA Aerospace Sciences Meeting and Exhibit. Reno, Nevada.

5. Mohr, M., D. Paulus, H. Baier, and M. Hornung. 2012. Design of a 450 passenger blended wing body aircraft for active control investigations. J. Aerospace Eng. 226(12).

6. Mohr, B., K. Plötner, and C. Rößler. ACFA 2020 WP 1. Final Report. Munich.

7. LABG mbH. 2008. Luftfahrttechnisches Handbuch (LTH). Ottobrunn.

8. Malone, B., and W. H. Mason. 1995. Multidisciplinary optimization in aircraft design using analytic technology models. J. Aircraft 32(2):431-38.

9. Staudacher, W. 2011. ACFA BWB conceptual design calculations. Munich.

10. Schemensky, R. T. 1973. Development of an empirically based computer program to predict the aerodynamic characteristics of aircraft. Air Force Flight Dynamics Laboratory AFFDL-TR-73-144. 
11. Stroscher, F., Ö. Petersson, and H. Baier. 2009. D 1.3 Part 2: Structural design of the ACFA 2020 CWB configuration. Munich.

12. Paluch, B., and D. Joly. 2010. D 1.2 Part 1: Design steps of the BWB finite element model. Lille: ONERA.

13. Langer, H. 2005. Extended evolutionary algorithms for multiobjective and discrete design optimization of structures. Munich.

14. Petersson, Ö., F. Stroscher, and H. Baier. 2010. Multidisciplinary optimisation of aircraft wings including gust loads. 2nd Aircraft Structural Design Conference. London: Royal Aeronautical Soc. Paulus, Salmon et al., Configuration Selection for a 450 Passenger Ultra-Efficient 2020 Aircraft

15. Salmon, T. 2009. Comparison dossier of the two 450 passenger aircraft configurations for ACFA2020. ACFA 2020 D1.5. Chatillon. 